\title{
OPTIMAL ASSIGNMENT OF VEHICLES TO URBAN TRANSPORT ROUTES
}

The article deals with solving a concrete problem occurring in the tramway net conditions in Ostrava urban mass transport. Nowadays a certain tramway set is in the traffic, where different vehicle types in terms of the capacity are assigned. For every route, one vehicle type is used. Information about the offered capacity and the passenger flows per hour is known. But the existing assignment of vehicles to single routes causes a greater discrepancy in terms of offered places and passengers' demand. The discrepancy can be measured by means of the ratio of these values on the most frequented route section. The discrepancy is characterized so that the ratios have very large deviation. In practice, it means that on the one hand there are routes with a high traveling comfort and on the other hand there are routes with a low traveling comfort. We can improve the situation by changing the vehicle types on single routes. At the same time we can reach the quality by improving offered services.

Keywords: Mathematical model, linear programming, urban public transport.

\section{Introduction - motivation to solve the problem}

The article deals with the problem of assigning the vehicle types to existing routes. The problem arises from the traffic practice in Ostrava where tram transport is an important part of urban public transport. The timetable is designed for every route that is carried out and the numbers of vehicles serving the particular routes are known. It is assumed in our case that each existing route has to be operated only by a specified tramset.

Let us define our main issue. In the real traffic there is often a situation that for some routes the excess of offered places over the demand is considerably big and for other routes the excess is negligible. It means that for some routes the passengers' comfort is higher than for other routes. It is known that this state is quite common in urban public transport. Nevertheless, in Ostrava such a situation causes the travelers' dissatisfaction because the disproportion is quite great. The municipal government of Ostrava, which prefers the tram transport, wants to achieve this disproportion to be as low as possible. Therefore, it is necessary to solve the task. We would like to assign the tramsets to the existing routes in order to reduce this disproportion.

\section{State of the art}

Urban public transport belongs to the basic forms of transport systems in every developed country. Well working urban public transport significantly influences sustainable development of areas not only in the view of transportation systems but also in the view of the entire region. Therefore, it should be an inseparable part of regional development programs. From the scientific point of view it is necessary to include it into integration theory of sustainable regional development which is, for example, mentioned in publication [1].

In source [2] it is said that it is necessary to use conceptual approach to all processes done at the city level. Cooperative negotiations of all participating sectors - public, business and civil sector - are necessary condition of such conceptual approach. All factors completely hold for creating the city public transportation system. In general, the city public transportation system has to meet some standards. The system has to be reliable, fast, safe and comfortable and with accessible fares [3], passengers have to be also properly informed about all important information relating the timetable, the fares and so on [4]. Some authors - for example in publication [5] - point out three pillars of the public transport sustainable development - economic, social and ecological. The requirement of accessibility of city public transport stops is also not insignificant as it is mentioned in [6]. Based on surveys done in three selected regions of the Czech Republic it was found out that in the case of commuting to work walking distances constitute up to 24-30 percent of total transport time. It is obvious that such level of accessibility substantially contributes to decreasing city public transport comfort and its competitiveness with individual car transport. Enlarging city territories and also areas served by city public transport imposes increasing requirements on planning city public transport operation.

Nowadays, creating large and high effective city public transportation systems cannot be done without using mathematical models and advanced information technologies. It is still a current

\footnotetext{
* Dusan Teichmann, Michal Dorda, Ivana Olivkova,

Faculty of Mechanical Engineering, Institute of Transport, VSB - TU Ostrava, Czech Republic, E-mail: dusan.teichmann@vsb.cz.
} 
issue therefore a lot of works presented in international papers [7], [8], [9] or [10] are focused on the task. However, the first publications devoted to our problem were released relatively long ago. One of the first proposals created on the basis of mathemat ical model was published by Erlander and Scheele [11]. Routes were chosen using binary variables. But the proposed model was nonlinear; therefore, its solving was significantly complicated. Another approach is represented by the model PRIVOL published in [12] [13] or [14]. The models based on the model PRIVOL were linear that means they were easier to solve. In [12] a PRIVOL model modification was introduced enabling minimization of the total number of vehicles needed for servicing the routes of the network for the first time. The original models [13] or [14] dealt with determination of the routes capacity. Solving the model we get the information about places offered for each route. The original models PRIVOL served as the inspiration for many similar models formed later; some of them were applied in the practice - see [15], [16] In publications [17] or [18] a multicriterial mathematical model intended for proposing public transport routes is published, it is one of possible multicriterial models. In work [19] the vehicles are assigned to routes directly for the case of a heterogeneous vehicle fleet. In article [20] the model, which was published in [19], was extended. The model assigns the required vehicle number to routes and, moreover, enables to find such a solution that it can be possible to create the timetable without any problems. That means each route has a regular headway in the timetable created on the basis of the solution of the model. All the above mentioned models require creating an input set of routes. The authors of contribution [21] showed the possibility how to create such input set of routes using linear programming. The column generation method was applied to get the input set of routes [7], [21].

But all the above mentioned models have one common and basic disadvantage in the case of our problem solution. It can happen that no vehicle will be assigned to a route. But in practice it is not an admissible situation. As in our case it is exactly known which route will be run and how many vehicles will be assigned to it. And we would like to solve the problem how to determine which vehicle type shall be assigned to each existing route. First, we will formulate the model in its general state.

\section{Mathematical model}

Let $L$ be the set of routes which are run. Let $M$ be the length of the longest route in the network. Let the length $m_{l}$ of a route section with the maximal (decisive) passenger flow $q_{l}$ per hour and the frequency on the route $w_{l}$ per hour be given for each $l \in L$. Let assume that the scheduling of tramsets is given for every route $l \in L$; that means we know how many tramsets run on the route $V_{l}$. We consider that tramsets are assigned only to a single route that means they do not serve trips of other routes. Ostrava Transport, joint-stock co. has several types of tramcars, let us assume that the set of tramcar types is denoted $I$. The tramcar type for each $i \in I$ can be identified by homogeneous technical parameters such as the number of places for sitting or standing passengers etc It is assumed that the number of places for sitting or standing pas- sengers in all vehicles type $i \in I$ is given; let us denote it $P_{i}$. For some tramcar types it is allowed to create several tramsets. Let $J_{i}$ be the set of tramsets which can be created from the tramcar type $i \in I$. For every tramset the capacity $k_{i j}$ is known where $i \in I$ and $j \in J$. Now, some of tramsets can be considered to be replaceable. Let $S$ be the set of all groups of replaceability. Further, let $I_{s}$ be the set of tramcars which can create tramsets for each $s \in S$ and $J_{s i}$ the set of tramsets formed from the $i$-th tramcar in the group of replaceability $s$. The detailed explanation of symbols $I_{s}, J_{i}$ and $J_{s i}$ will be listed in the experimental part.

In our case we shall decide about assigning the number of tramsets from the subsets of the set $S$ to the each existing route. Furthermore, we have to decide how many tramsets will be created from individual types of tramcars.

In order to keep a certain level of passengers' comfort we can determine a capacity coefficient $r_{l}$ for each route $l \in L$. Multiplying the maximal passenger flow $q_{l}$ by the coefficient $r_{l}$ we get certain capacity of free places. There are several approaches to determine the value $r_{l}$, where $l \in L$. The simplest way how to determine it is to multiply the maximal passenger flow $q_{\text {, }}$ by a predefined constant. But from the practical view this approach is not suitable. It is also necessary to take into account the route section length on which the maximal (or we can say decisive) passenger flow is. If the route section with the maximal passenger flow is not long then passengers are usually willing to accept the lower level of comfort. To calculate the coefficient $r_{l}$ for the route $l \in L$ we can use, for example, the following formula:

$$
r_{l}=\left(1+\frac{m_{l}}{M}\right) .
$$

To solve our case, mathematical programming was used. In the paper we will present a mathematical model created in order to solve our problem. In model (2) - (11) we will use following groups of variables: $N_{l i j}$ is the number of tramsets $j$ formed from tramcar $i$ and assigned to route $l, u$ is the value of maximal excess of the offer over the demand and $z_{l s}$ is a binary variable modeling assignment of group of replaceability $s$ to the route $l$. It is possible to formulate general mathematical model (2) - (11) for the problem solution in the form:

$$
\min f(u)=u
$$

$$
\begin{array}{cc}
\text { subject to: } \sum_{i \in I} \sum_{j \in J_{l}} N_{l i j}=V_{l} & \text { for } l \in L \\
\frac{w_{l}}{V_{l}} \sum_{i \in I} \sum_{j \in J_{l}} N_{l i j} k_{i j}-r_{l} q_{l} \leq u & \text { for } l \in L \\
\frac{w_{l}}{V_{l}} \sum_{i \in I} \sum_{j \in J_{l}} N_{l i j} k_{i j} \geq r_{l} q_{l} & \text { for } l \in L \\
\sum_{i \in I} \sum_{j \in J_{l}} N_{l i j} k_{i j} \leq P_{l} & \text { for } i \in I
\end{array}
$$




$$
\begin{aligned}
& \sum_{s \in S} z_{l s}=1 \quad \text { for } l \in L \\
& \sum_{i \in I_{s}} \sum_{j \in J_{s i}} N_{l i j} \leq T z_{l s} \quad \text { for } l \in L \text { and } s \in S \\
& N_{l i j} \in Z_{0}^{+} \quad \text { for } l \in L, i \in I \text { and } j \in J_{i} \\
& u \geq 0 \\
& z_{l s} \in\{0 ; 1\} \quad \text { for } l \in L \text { and } s \in S
\end{aligned}
$$

The function (2) represents the objective function - the value of maximal excess of the offer over the demand - that is minimized. Constraints (3) assure that the proposed number of tramsets will be assigned on every route. Constraints (4) form link between the objective function and the constraints. Constraints (5) ensure that the number of offered places will be enough for each route. Constraints (6) assure not exceeding the vehicle fleet capacity for each tramcar type. Constraints (7) assure that every route will be served only with tramsets from a single group of replaceability. Constraints (8) form required logic links between variable groups $N_{l i j}$ and $z_{l j}$ (the value $T$ is called prohibitive constant). Constraints (8) - (11) define obligatory constraints.

\section{Experimental part}

The proposed mathematical model will be tested under the conditions of a real network of routes, in which the mentioned problem occurs. The problem occurs mainly during daylight hours of weekend days. The basic information about the vehicle fleet of Ostrava Transport, joint-stock co., is shown in Table 1. Groups of replaceability and possible tramsets within each set were created based on vehicle fleet knowledge - see Table 2 . When creating the groups of replaceability we went out of the tramsets interoperability in the conditions of Ostrava Transport, joint-stock co. The interoperability of tramsets is listed in Table 2. The groups of replaceability were created in accordance with everyday practice in the transport company. Furthermore, we know that 10 tram routes are operated in the daylight hours of weekend days. To realize the optimization experiments it was necessary to find for every route values of the following parameters: the route length, the length of section with decisive intensity, the number of tramsets which have to be assigned to each route according to the timetable, passenger flow on decisive section per hour (rounded). The basic input information about routes required for optimization is summarized in Table 3. We calculated the offered route capacity as the product of the number of trips that serve the route per hour and the capacity of tramsets assigned to the route. We know that three trips per hour are run on every route according to the current timetable. In Table 3, further information regarding the traffic routes is listed. Namely, there are route lengths and the lengths of sections with decisive flow. As can be seen, the length of the longest route is equal to $16.3 \mathrm{~km}$ - it is the value denoted $M$. Based on the parameter $M$ and the length of section with decisive flow the reserve is calculated according to equation (1). As can be seen from the sixth column of Table 3, the maximal excess of places for route per hour is 507 places in the current case.

Information about tramcars capacity

Table 1

\begin{tabular}{|c|c|c|c|}
\hline $\begin{array}{c}\text { Type } \\
\text { number }\end{array}$ & $\begin{array}{c}\text { Type } \\
\text { of tramcar }\end{array}$ & $\begin{array}{c}\text { Tramcar capacity } \\
\text { [places] }\end{array}$ & $\begin{array}{c}\text { Total capacity } \\
\text { [places] }\end{array}$ \\
\hline 1 & T3 & 103 & 15244 \\
\hline 2 & T6A5 & 115 & 4370 \\
\hline 3 & LFR.E & 93 & 3069 \\
\hline 4 & ASTRA & 154 & 2156 \\
\hline 5 & TRIO & 199 & 1791 \\
\hline 6 & T3R.EV & 110 & 110 \\
\hline 7 & K2 & 157 & 1256 \\
\hline 8 & KT8D5 & 231 & 3696 \\
\hline 9 & LF2 & 140 & 140 \\
\hline 10 & LF3 & 229 & 458 \\
\hline 11 & LF3/2 & 229 & 229 \\
\hline 12 & LF2 plus & 143 & 143 \\
\hline
\end{tabular}

Information about tramsets capacity

Table 2

\begin{tabular}{|c|c|c|}
\hline $\begin{array}{c}\text { Group of } \\
\text { replace-ability }\end{array}$ & Tramset & $\begin{array}{c}\text { Tramset capacity } \\
\text { [places] }\end{array}$ \\
\hline \multirow{4}{*}{1} & T3 & 103 \\
\cline { 2 - 3 } & T6A5 & 115 \\
\cline { 2 - 3 } & T3R.EV & 110 \\
\hline \multirow{4}{*}{2} & LFR.E & 93 \\
\cline { 2 - 3 } & $2 \times$ T3 & 206 \\
\cline { 2 - 3 } & $2 \times$ T6A5 & 230 \\
\hline \multirow{4}{*}{3} & $2 \times$ T3R.EV & 220 \\
\cline { 2 - 3 } & K2 & 157 \\
\cline { 2 - 3 } & LF2 & 140 \\
\hline \multirow{3}{*}{4} & LF2 plus & 143 \\
\cline { 2 - 3 } & ASTRA & 154 \\
\hline \multirow{3}{*}{5} & TRIO & 199 \\
\cline { 2 - 3 } & KT8D5 & 231 \\
\cline { 2 - 3 } & LF3 & 229 \\
\hline
\end{tabular}

Now we specify the sets $I, J_{i}, I_{s}$ and $J_{s i}$ in our case. We have 12 tramcar types and 5 groups of replaceability. The corresponding sets are: 


\begin{tabular}{|c|c|c|c|c|c|c|c|c|}
\hline $\begin{array}{c}\text { Route } \\
{[-]}\end{array}$ & $\begin{array}{l}\text { Number of } \\
\text { assigned } \\
\text { tramsets [-] }\end{array}$ & $\begin{array}{c}\text { Capacity of } \\
\text { current tramset } \\
\text { [places] }\end{array}$ & $\begin{array}{l}\text { Offered route } \\
\text { capacity per } \\
\text { hour } \\
\text { [places } \cdot \mathrm{h}^{-1} \text { ] }\end{array}$ & $\begin{array}{c}\text { Traveller flow on } \\
\text { decisive section } \\
\text { per hour [passen- } \\
\text { gers } \cdot h^{-1} \text { ] }\end{array}$ & $\begin{array}{c}\text { Current excess } \\
\text { of places on the } \\
\text { route per hour } \\
\text { [places] }\end{array}$ & $\begin{array}{l}\text { Route length } \\
\qquad[\mathrm{km}]\end{array}$ & $\begin{array}{c}\text { Length of } \\
\text { section with } \\
\text { decisive flow } \\
{[\mathrm{km}]}\end{array}$ & $\begin{array}{c}\text { Proposal } \\
\text { capacity } \\
\text { coefficient } \\
{[-]}\end{array}$ \\
\hline 1 & 4 & 230 & 690 & 405 & 285 & 11.7 & 5.1 & 1.31288 \\
\hline 2 & 5 & 157 & 471 & 390 & 81 & 12.7 & 4.5 & 1.27607 \\
\hline 3 & 5 & 199 & 597 & 90 & 507 & 15.8 & 9.4 & 1.57669 \\
\hline 4 & 4 & 103 & 309 & 120 & 189 & 12.6 & 5.3 & 1.32515 \\
\hline 7 & 5 & 206 & 618 & 290 & 328 & 14.0 & 7.1 & 1.43558 \\
\hline 8 & 5 & 154 & 462 & 300 & 162 & 13.8 & 3.8 & 1.23313 \\
\hline 9 & 5 & 103 & 309 & 130 & 179 & 16.3 & 5.7 & 1.34969 \\
\hline 11 & 5 & 93 & 279 & 80 & 199 & 12.5 & 10.5 & 1.64417 \\
\hline 12 & 5 & 154 & 462 & 150 & 312 & 14.8 & 7.2 & 1.44172 \\
\hline 17 & 5 & 230 & 690 & 480 & 210 & 13.5 & 5.3 & 1.32515 \\
\hline
\end{tabular}

Results of optimization experiments

Table 4

\begin{tabular}{|c|c|c|c|c|c|c|c|c|c|c|c|c|c|c|c|c|c|c|c|c|c|}
\hline & \multicolumn{1}{|c|}{ Numerical experiment number 1} \\
\hline Route number/tramset & 1 & 2 & 3 & 4 & 7 & 8 & 9 & 11 & 12 & 17 & 1 & 2 & 3 & 4 & 7 & 8 & 9 & 11 & 12 & 17 \\
\hline TR3 & - & - & 1 & 4 & 5 & 5 & 5 & - & 5 & - & - & - & - & 3 & - & - & 5 & - & 5 & - \\
\hline 2xTR3 & & 5 & - & - & - & - & - & - & - & 5 & 4 & 5 & - & - & - & - & - & - & - & 5 \\
\hline LFR.E & - & - & 4 & - & - & - & - & 5 & - & - & - & - & 5 & 1 & - & - & - & 5 & - & - \\
\hline ASTRA & 2 & - & - & - & - & - & - & - & - & - & - & - & - & - & 2 & - & - & - & - & - \\
\hline TRIO & 2 & - & - & - & - & - & - & - & - & - & - & - & - & - & 3 & - & - & - & - & - \\
\hline K2 & - & - & - & - & - & - & - & - & - & - & - & - & - & - & - & 4 & - & - & - & - \\
\hline LF2 & - & - & - & - & - & - & - & - & - & - & - & - & - & - & - & 1 & - & - & - & - \\
\hline Number of assigned tramsets & 4 & 5 & 5 & 4 & 5 & 5 & 5 & 5 & 5 & 5 & 4 & 5 & 5 & 4 & 5 & 5 & 5 & 5 & 5 & 5 \\
\hline
\end{tabular}

$I=\{T 3, T 6 A 5, L F R . E, A S T R A, T R I O, \ldots, L F 2$ plus $\}$

$J_{i}: J_{1}=\{T 3,2 x T 3\}, J_{2}=\{T 6 A 5,2 \times T 6 A 5\}$, etc.,

$I_{s}: I_{1}=\{T 3, T 6 A 5, T 3 R . E V$, LFR.E $\}$,

$I_{2}=\{T 3, T 6 A 5, T 3 R . E V\}$, etc.,

$J_{s i}: J_{11}=\{T 3\}, J_{12}=\{T 6 A 5\}, \ldots, J_{21}=\{2 x T 3\}$,

$J_{22}=\{2 \times T 6 A 5\}$, etc.

At this moment we can begin with optimization computations. All the calculations were performed using optimization software Xpress-IVE.

In computation number 1 we considered the reserve $r_{l}=1$ for each route $l \in L$. The calculation number 2 was made with mathematical model (2) - (11) as well. The difference was that we did not consider the reserve value $r_{l}=1$ for each route $l \in L$ but we used the value which was calculated by formula (1). After the calculation the following results were obtained, see Table 4. In the table there are only those tramsets which were assigned to routes.
The excess of offered places before and after optimization Table 5

\begin{tabular}{|c|c|c|c|}
\hline $\begin{array}{c}\text { Route } \\
{[-]}\end{array}$ & $\begin{array}{c}\text { The excess of } \\
\text { offered places } \\
\text { before } \\
\text { optimization } \\
{\left[\text { places } \cdot \mathrm{h}^{-1}\right]}\end{array}$ & $\begin{array}{c}\text { The excess of } \\
\text { offered places } \\
\text { after optimization } \\
\left(r_{l}=1\right) \\
{\left[\text { places } \cdot \mathrm{h}^{-1}\right]}\end{array}$ & $\begin{array}{c}\text { The excess of } \\
\text { offered places after } \\
\text { optimization; the } \\
\text { value is calculated } \\
\text { using formula }(1) \\
{\left[\text { places } \cdot \mathrm{h}^{-1}\right]}\end{array}$ \\
\hline 1 & 285 & 125 & 87 \\
\hline 2 & 81 & 72 & 121 \\
\hline 3 & 507 & 195 & 138 \\
\hline 4 & 189 & 189 & 143 \\
\hline 7 & 328 & 19 & 127 \\
\hline 8 & 162 & 9 & 91 \\
\hline 9 & 179 & 179 & 134 \\
\hline 11 & 199 & 199 & 148 \\
\hline 12 & 312 & 159 & 93 \\
\hline 17 & 210 & 138 & 54 \\
\hline
\end{tabular}


The original value of the objective function - the maximal excess of offered places over the decisive passenger flow per hour - was 507 places for sitting and standing. For numerical experiment number 1 the value of the objective function is 199 places and 148 places (after rounding up) for numerical experiment number 2. The situation for single routes before and after optimization can be seen in the Table 5 . In Table 5 the excess of offered places over the decisive passenger flow per hour for every route is summarized.

\section{Conclusion}

The paper deals with the problem of uniform allocation of tram-sets on existing routes of the public transport network. The experiments with proposed model were made in the conditions of the tram network operated by Ostrava Transport, joint-stock co. By solving the presented models we balanced the excess of places offered on the existing lines. Hierarchical min-max approach could be mentioned as a possible future research direction.

\section{References}

[1] VITURKA, M.: Integration Theory of Sustainable Regional Development - Presentation and Application (in Czech). Politicka ekonomie, 2011, vol. 59, No. 6, pp. 794-809.

[2] JEZEK, J.: City Marketing - Concepts, Application, Critical Analysis (in Czech), Journal of Economics (Ekonomicky casopis), 2011, vol. 59, No. 3, pp. 243-258.

[3] SUROVEC, P.: Urban Mass Transport System Creation (in Slovak). Zilina: University of Zilina, 1999.

[4] OLIVKOVA, I.: Passenger Information Systems in Public Transport, Communications - Scientific Letters of the University of Zilina, 2008, vol. 10, No. 3, pp. 269-71.

[5] CERNA, A.: Economic and Social Harmonization of Sustainable Public Transport, Prague Economic Paper, 2012, vol. 21, no. 1, pp. 83-100.

[6] IVAN, I.: Walking to a Transport Stop and its Influence on Commuting (in Czech), Geografie, 2010, vol. 115, No. 4, pp. 393-412,

[7] BORNDOERFER, R., GROETSCHEL, M., PFETSCH, M. E.: A Column-generation Approach to Line Planning in Public Transport, Transportation Science, 2007, vol. 41, No. 2, pp. 123-132.

[8] BUSSIECK, M., R., KREUZER, P., ZIMMERMANN, U., T.: Optimal Lines for Railway System, European J. of Operation Research, 1997, vol. 96, No. 1, pp. 54-63.

[9] DELLOLIO, L., IBEAS, A., RUISANCHES, F.: Optimizing bus-size and headway in transit networks, Transportation, 2012 , vol. 39, no. 2, pp. 449-464.

[10] SHIMAMOTO, H., MURAYAMA, N., FUJIWARA, A., ZHANG, J.: Evaluation of an Existing Bus Network Using a Transit Network Optimization Model: A Case Study of the Hiroshima City Bus Network, Transportation, 2010, vol. 37, No. 5, pp. 801-823.

[11] ERLANDER, S., SCHEELE, S.: A Mathematical Programming Model for Bus Traffic in a Network. Proceedings Transportation and Traffic Theory, Sydney : REED, 1974

[12] CERNY, J.: Poznamka k jednotnym intervalom v systemoch MHD [Note on Uniform Intervals of Urban Public Transport], Proceedings of the works, Zilina: VUD, 1983.

[13] CERNY, J., KLUVANEK, P.: Basic of Mathematical Transport Theory (in Slovak), Bratislava: VEDA, 1990.

[14] CERNA, A., CERNY, J.: Management and Decision Theory in Transport Systems (in Czech), Pardubice: Institut Jana Pernera, 2004.

[15] PALUCH, S., MAJER, T.: Urban and Regional Periodical Transport Optimization (in Slovak), Proc. of Intern. Conference Vysoka skola jako facilitator rozvoje spolecnosti a regionu, European Polytechnic Institute Kunovice, 2007.

[16] PESKO, S.: Support of Operations Research Methods for Line System Design, Proc. of ${ }^{\text {th }}$ Intern. Conference Urban Transportation Infrastructure, Zilina, 2008.

[17] JANOSIKOVA, L., BLATON, M., TEICHMANN, D.: Design of Urban Public Transport Lines as a Multiple Criteria Optimization Problem. Proc. of the conference "Urban Transport 2010", Cyprus, 2010.

[18] JANOSIKOVA, L., KOHANI, M., BLATON, M, TEICHMANN, D.: Optimization of the Urban Line Network Using a Mathematical Programming Approach, International Journal of Sustainable Development and Planning, 2012, vol. 7, No. 3, pp. 288-301.

[19] DANEK, J., PLEVNY, M., TEICHMANN, D.: The Rational Operation of the Urban Transport Line Network by Minimization of the Need Vehicles, E+M Economics and Management, 2010, vol. 13, No. 2, pp. 53-62.

[20] TEICHMANN, D., DORDA, M., FRIC, J.: An Extended Model for the Design of City Mass Transport Network, Proc. of the Mathematical Methods in Economics 2011, Janska dolina, 2011.

[21] JANACEK, J., SIRC, J.: The Column Generation Technique for Public Transport Line Planning by IP Solver, Communications Scientific Letters of the University of Zilina, vol. 12, No. 3a, 2010, pp. 60-64. 